\title{
Hybrid Beads of Zero Valent Iron Oxide Nanoparticles and Chitosan for Removal of Arsenic in Contaminated Water
}

\author{
Mian Fawaz Ahmed ${ }^{1}$, Muhammad Asad Abbas ${ }^{1}$, Azhar Mahmood ${ }^{2} \mathbb{D}$, Nasir M. Ahmad ${ }^{1, *}$, Hifza Rasheed ${ }^{3}$, \\ Muhammad Abdul Qadir ${ }^{4}$, Asad Ullah Khan ${ }^{5}$, Hazim Qiblawey ${ }^{6}{ }^{\mathbb{D}}$, Shenmin Zhu ${ }^{7}$, Rehan Sadiq ${ }^{8}$ \\ and Niaz Ali Khan $9,10, *$
}

check for updates

Citation: Ahmed, M.F.; Abbas, M.A.; Mahmood, A.; Ahmad, N.M.; Rasheed, H.; Qadir, M.A.; Khan, A.U.; Qiblawey, H.; Zhu, S.; Sadiq, R.; et al. Hybrid Beads of Zero Valent Iron Oxide Nanoparticles and Chitosan for Removal of Arsenic in Contaminated Water. Water 2021, 13, 2876. https:// doi.org/10.3390/w13202876

Academic Editor: Antonio Panico

Received: 28 July 2021

Accepted: 15 September 2021

Published: 14 October 2021

Publisher's Note: MDPI stays neutral with regard to jurisdictional claims in published maps and institutional affiliations.

Copyright: (c) 2021 by the authors. Licensee MDPI, Basel, Switzerland. This article is an open access article distributed under the terms and conditions of the Creative Commons Attribution (CC BY) license (https:/ / creativecommons.org/licenses/by/ $4.0 /)$.
1 Polymer Research Lab, School of Chemical and Material Engineering, National University of Sciences and Technology (NUST), Islamabad 44000, Pakistan; mianfawaz@gmail.com (M.F.A.); engr.ma.abbas@live.com (M.A.A.)

2 School of Natural Sciences, National University of Sciences and Technology (NUST), Islamabad 44000, Pakistan; dr.azhar@sns.nust.edu.pk

3 National Water Quality Laboratory, Pakistan Council of Research in Water Resources, Islamabad 44000, Pakistan; pcrwr2005@yahoo.com

4 The Institute of Chemistry, University of the Punjab, Quaid-e-Azam Campus, Lahore 54770, Pakistan; mabdulqadir.chem@pu.edu.pk

5 Department of Chemical Engineering, COMSATS University Islamabad, Lahore Campus, Lahore 54000, Pakistan; asadkhan@cuilahore.edu.pk

6 Department of Chemical Engineering, College of Engineering, Qatar University, Doha P.O. Box 2713, Qatar; hazim@qu.edu.qa

7 State Key Laboratory of Metal Matrix Composites, Shanghai Jiao Tong University, Shanghai 200240, China; smzhu@situ.edu.cn

8 Faculty of Applied Sciences, School of Engineering, University of British Colombia, Okanagan Campus, Kelowna, BC V1V 1V7, Canada; rehan.sadiq@ubc.ca

9 School of Chemical Engineering and Technology, Tianjin University, Tianjin 300072, China

10 Nova Materials Technologies, Lahore 54900, Pakistan

* Correspondence: nasir.ahmad@scme.nust.edu.pk (N.M.A.); niaz@tju.edu.cn (N.A.K.)

\begin{abstract}
Water contaminated with highly hazardous metals including arsenic (As) is one of the major challenges faced by mankind in the present day. To address this pressing issue, hybrid beads were synthesized with various concentrations of zero valent iron oxide nanoparticles, i.e., $20 \%$ (FeCh-20), 40\% (FeCh-40) and 60\% (FeCh-60) impregnated into a polymer of chitosan. These hybrid beads were employed as an adsorbent under the optimized conditions of $\mathrm{pH}$ and time to facilitate the efficient removal of hazardous arsenic by adsorption cum reduction processes. X-ray Diffraction (XRD), Scanning Electron Microscopy (SEM), Fourier Transform Infrared Spectroscopy (FTIR), Brunauer- Emmett-Teller BET, a porosity test and wettability analysis were performed to characterize these hybrid beads. The porosity and contact angle of the prepared hybrid beads decreased with an increase in nanoparticle concentration. The effects of various adsorption factors such as adsorbent composition, contact period, $\mathrm{pH}$ value and the initial adsorbate concentration were also evaluated to study the performance of these beads for arsenic treatment in contaminated water. FeCh-20, FeCh-40 and FeCh-60 have demonstrated $63 \%, 81 \%$ and $70 \%$ removal of arsenic at optimized conditions of $\mathrm{pH} 7.4$ in $10 \mathrm{~h}$, respectively. Higher adsorption of arsenic by FeCh-40 is attributed to its optimal porosity, hydrophilicity and the presence of appropriate nanoparticle contents. The Langmuir adsorption kinetics described the pseudo second order. Thus, the novel beads of FeCh-40 developed in this work are a potent candidate for the treatment of polluted water contaminated with highly toxic arsenic metals.
\end{abstract}

Keywords: zero valent iron oxide; chitosan; nanoparticles; arsenic; adsorption; isotherm model; kinetics 


\section{Introduction}

Contamination of water bodies is one of the crucial hazardous factors affecting the well-being of our earth and its inhabitants. The environment, economic growth, and development are sacrificially affected by a sub-standard quality of surface and ground water. Contamination of water by toxic elements such as $\mathrm{Cr}, \mathrm{Pb}, \mathrm{Hg}, \mathrm{Cd}$ and As, etc., is among the major threats to the health of human beings as well as aquatic and terrestrial life [1]. Generally, heavy metals are water soluble, and hence, have facile mobilization in the environment. Arsenic is one of the elemental pollutants that has caused significant harm to aquatic and human health. As per World Health Organization (WHO) guidelines, $10 \mu \mathrm{g} / \mathrm{L}$ is a permissible arsenic limit for potable water [2]. Arsenic-contaminated drinking water can cause various health problems such as skin lesions, lung carcinoma, and cardiovascular ailments. Worldwide, about 150 million people are affected by arsenic-contaminated aquifers. In Pakistan, the situation is even more critical due to high $\mathrm{pH}$ dissolution of arsenic from basic surface soil into Arid Indus areas and substantial irrigation by these contaminated aquifers, thus posing a threat to the health of 50-60 million people using subterranean water in this region [3]. These figures are distressing and call for appropriate mitigation measures.

Various conventional methods are employed for arsenic treatment in water including adsorption [4], extraction [5], reverse osmosis, oxidation [6], electrodeposition [7], ion exchange resin and membrane screening [8]. There is room for improvement in terms of duration, effectiveness, adsorption capacity and cost to broaden the scope of these techniques for water treatment applications [9]. Recently, the adsorption technique has become the most promising wastewater treatment method, being economical, environment friendly, easy to operate, flexible and devoid of by-products as well as having the possibility of regenerating the adsorbent for reuse up to a feasible number of cycles $[10,11]$. However, the use of adsorbents for pollutant removal has its challenges, such as the limited number of adsorbent materials available for column configuration and their non-suitability for different types of pollutant in wastewater. These shortcomings can be minimized by employing macromolecules and nanoparticles capable of deep particle adsorption, thus increasing the diffusion rate by increasing the surface area of the adsorbent [12]. Various nanoparticles have been used as adsorbents such as activated carbon, silver [13], aluminum oxide, titanium oxide [14], polymer and metal oxide [15]. Due to the high affinity and selectivity of iron oxide nanoparticles toward arsenic, they are considered highly efficient for the adsorption of arsenic. However, the inadequate fabrication of iron oxide into a bead structure limits its application in the column adsorbent bed. Combining iron oxide with environmentally benign functional biopolymers may address this challenge. Chitosan is a carbohydrate polymer that has a benign nature, natural occurrence, is nontoxic, biocompatible, biodegradable, environmentally friendly, and feasible to process into films and beads. Moreover, it is able to form a complex with heavy metals in water owing to the presence of amino and hydroxyl groups [16,17]. However, it faces some challenges such as high swelling behavior and nonporous texture that contribute towards a reduction in adsorption capacity. This can be overcome by developing a hybrid material through the incorporation of NPs impregnated into chitosan [14,18].

Herein, we report on combining the above-mentioned advantages of nano zero valent iron oxide particles (NZVI) and chitosan to develop hybrid beads of optimum composition for effective arsenic treatment in contaminated water [19]. NZVI particles impregnated into the chitosan matrix synergistically increased adsorbent efficiency for arsenic in aqueous media. These hybrid beads were characterized to study their chemical structures, morphology, porosity, and surface wettability [20]. The performance of the hybrid beads was measured with respect to various parameters such as initial arsenic concentration, time and $\mathrm{pH}$. Various theorems such as pseudo first order, pseudo second order, Langmuir and Freundlich isotherms were applied to study the adsorption mechanism. 


\section{Experimental Work}

\subsection{Materials}

Iron chloride hexa-hydride $\left(\mathrm{FeCl}_{3} \cdot 6 \mathrm{H}_{2} \mathrm{O}\right)$ (Sigma-Aldrich, $\left.\mathrm{Mw}=270.30 \mathrm{~g} / \mathrm{mol}\right)$, chitosan $\mathrm{Mw}=\left(4.9 \times 10^{5}\right)$ (Sigma-Aldrich), ethylene glycol (Sigma-Aldrich, Germany, $\mathrm{Mw}=62 \mathrm{~g} / \mathrm{mol}$ ), and sodium acetate (Sigma-Aldrich, Germany, $\mathrm{Mw}=82 \mathrm{~g} / \mathrm{mol}$ ) were obtained commercially. Different aqueous solutions of Arsenic $(\mathrm{V})$ were made by dissolving pre-calculated amounts of arsenic $\left(\mathrm{As}_{2} \mathrm{O}_{5}\right.$, Sigma-Aldrich, $\left.\mathrm{Mw}=229.8 \mathrm{~g} / \mathrm{mol}\right)$ into ultra-pure water according to ASTM standards (D2972-08), while the $\mathrm{pH}$ of the medium was modified by adding the required concentration of a $\mathrm{NaOH}$ and $\mathrm{HCl}$ solution. All reagents and solvents used in this study were of analytical grade and used without further treatment unless specified.

\subsection{Synthesis of Iron Oxide Nanoparticles}

Iron oxide nanoparticles were prepared by a hydrothermal method [21]. Initially, sodium borohydride (the reducing agent) was dissolved into ethylene glycol $(72 \mathrm{~mL})$ containing distilled water. An iron chloride hexahydrate ( $3 \mathrm{~g}$ ) precursor was mixed into this solution under vigorous stirring followed by the addition of polyethylene glycol $(2 \mathrm{~g})$ and sodium acetate $(6 \mathrm{~g})$. The resultant reaction mixture was poured into a Teflon autoclave, kept in an oven at $200^{\circ} \mathrm{C}$ for $10 \mathrm{~h}$ and cooled down in ambient conditions. Magnetic iron oxide nanoparticles were retrieved out of the solution via a magnet, rinsed by distilled water multiple times until the $\mathrm{pH}$ was neutralized and freeze dried. The mechanism and synthesis of iron oxide nanoparticles are exhibited in Figure 1a,b, respectively.

$$
2 \mathrm{FeCl}_{3}+6 \mathrm{NaBH}_{4}+18 \mathrm{H}_{2} \mathrm{O} \rightarrow 2 \mathrm{Fe}^{0}+6 \mathrm{NaCl}+6 \mathrm{~B}(\mathrm{OH})_{3}+21 \mathrm{H}_{2}
$$

(a)
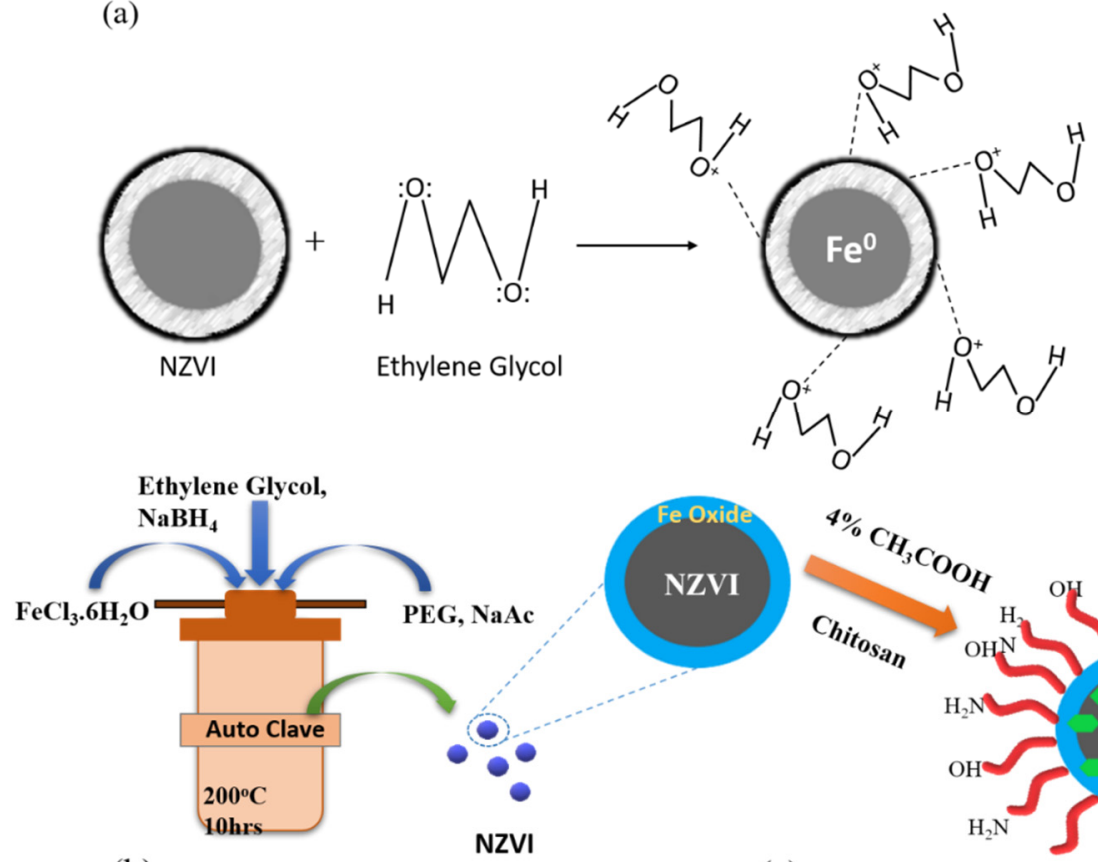

(b)

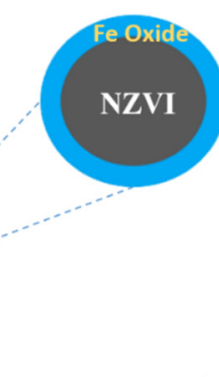

(c)

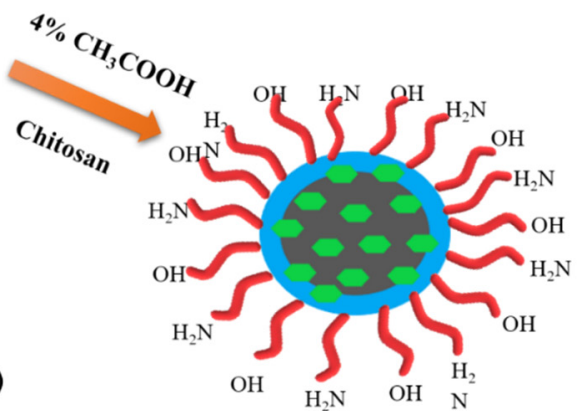

Figure 1. (a) Chemical equation and mechanism of nano zero valent iron oxide particles (NZVI) synthesis; (b) Scheme of NZVI synthesis; (c) Functionalization of NZVI by chitosan.

\subsection{Synthesis of Iron Oxide Impregnated Chitosan}

For preparation of hybrid beads, the template method was chosen [5]. Chitosan powder was dissolved into $4 \%$ acetic acid solution under continuous stirring overnight. Afterwards, various quantities of iron oxide nanoparticles were incorporated into the chitosan solution with vigorous stirring until the homogenous solution was obtained. The 
compositions of the different samples were as follows: FeCh-20 contained $1 \mathrm{~g}(20 \%)$ iron oxide NPs and $4 \mathrm{~g}(80 \%)$ chitosan; FeCh-40 consisted of $2 \mathrm{~g}(40 \%)$ iron oxide NPs and $3 \mathrm{~g}$ $(60 \%)$ chitosan; and FeCh-60 comprised $3 \mathrm{~g}(60 \%)$ iron oxide and $2 \mathrm{~g}(40 \%)$ chitosan. The resultant slurry was added dropwise into a $2 \mathrm{M}$ sodium hydroxide solution with the help of a syringe and stirred continuously until macro-sized spheres appeared. These macro spheres were separated using filter paper, rinsed using distilled water until $\mathrm{pH} 7$ was obtained and dehydrated in a heating oven at $60^{\circ} \mathrm{C}$ for $6 \mathrm{~h}$. The experimental procedures are demonstrated in Figure 1c.

\section{Characterization Techniques}

An X-ray diffractometer (STOE, Darmstadt, Germany) was employed to study the crystalline structure of NZVI- and NPs-impregnated chitosan beads before and after adsorption of arsenic. Samples were scanned at $0.5 \mathrm{~s} / \mathrm{step}$ in the $2 \theta$ range $10-90^{\circ}$ and the Debye -Scherrer equation was utilized to calculate crystallite size. Infrared absorptions were measured in a $4000-400 \mathrm{~cm}^{-1}$ wavenumber range by a Nicolet- 6700 spectrophotometer by ThermoFisher Scientific, Massachusetts, United States to investigate the functional moieties present in NZVI and hybrid beads. The surface morphology of prepared samples was also studied using a JEOL-JSM-6490LA (JEOL, Tokyo, Japan) scanning electron microscope. Porosity percentage was calculated via Archimedes' rule by using ethanol as a displacement fluid, while pore size was determined via the BET technique. In compliance with the protocols of Archimedes' rule, the average porosity of the hybrid beads of various samples was estimated by using the following equation [22]

$$
\epsilon=\frac{\mathrm{V}_{\mathrm{s}}}{\mathrm{V}_{\mathrm{p}}+\mathrm{V}_{\mathrm{s}}}
$$

where $\mathrm{Vs}$ is the volume of specimen $(\mathrm{mL}), \mathrm{Vp}$ is the volume of pores $(\mathrm{mL})$, and $\in$ shows the porosity of specimen.

The contact angle was measured by employing a sessile drop method at standard conditions. To restrict the spreading of each droplet's shape, contact angle values were recorded within 15-20 s after placing a drop on the surface of the beads. An atomic absorption spectrometer (AAS Vario 6, Analytik Jena, Germany) and an atomizer with a graphite furnace were used to analyze the concentration of arsenic in the samples. All analyses were performed using integrated absorbance. Argon was used as a purge gas for the analysis due to its inertness. The arsenic adsorption experiment was executed by applying the batch equilibrium technique. To study adsorption isotherm, $10-40 \mathrm{ppm}$ initial arsenic concentrations were employed at neutral $\mathrm{pH}(6.9 \pm 0.5)$ with a constant dose of hybrid beads $(1 \mathrm{~g} / \mathrm{L})$ in an Erlenmeyer flask under continuous stirring at $150 \mathrm{rpm}$. Adsorption of As $(\mathrm{V})$ was also studied as a function of $\mathrm{pH}$ by keeping the concentration of As $(10 \mathrm{ppm})$ and the adsorbent $(1 \mathrm{~g} / \mathrm{L})$ constant, while varying $\mathrm{pH}$. After the adsorption experiment, the remaining concentration of arsenic was measured by the AAS and various theorems were employed to analyze the experimental results. The adsorption efficiency of the prepared materials was calculated using the following equations:

$$
\begin{gathered}
\text { \%age Removal }=\left[\frac{\left(\mathrm{C}_{\mathrm{o}}-\mathrm{C}_{\mathrm{e}}\right)}{\left(\mathrm{C}_{\mathrm{o}}\right)}\right] \times 100 \\
\left(\mathrm{q}_{\mathrm{e}}\right)=\frac{\left[\left(\mathrm{C}_{\mathrm{o}}-\mathrm{C}_{\mathrm{e}}\right) \times \mathrm{V}\right]}{(\mathrm{m})} \\
\frac{\mathrm{C}_{\mathrm{e}}}{\mathrm{q}_{\mathrm{e}}}=\frac{1}{\mathrm{~K}_{\mathrm{L}} \times \mathrm{q}_{\mathrm{m}}}+\frac{\mathrm{C}_{\mathrm{e}}}{\mathrm{q}_{\mathrm{m}}} \\
\log (\mathrm{q})=\log \left(\mathrm{K}_{\mathrm{f}}\right)+\frac{1}{\mathrm{n}} \log \left(\mathrm{C}_{\mathrm{e}}\right)
\end{gathered}
$$


where " $\mathrm{q}_{\mathrm{e}}$ " is the adsorption capacity of beads $(\mathrm{mg} / \mathrm{g})$, " $\mathrm{V}$ " is the volume of solution $(\mathrm{L})$, " $\mathrm{m}$ " is the mass of adsorbent $(\mathrm{g})$, and " $\mathrm{C}_{\mathrm{o}}$ " and " $\mathrm{C}_{\mathrm{e}}$ " are the initial and final arsenic concentrations ( $\mathrm{mg} / \mathrm{L})$, respectively. The process of adsorption has also been expressed by Langmuir and Freundlich relations (Equations (3) and (4)). The logarithmic form of the Freundlich equation is expressed in Equation (5), where " $\mathrm{K}_{\mathrm{f}}$ " having unit $(\mathrm{mg} / \mathrm{g})$ is the Freundlich constant and " $n$ " is the Freundlich exponent.

$$
\begin{gathered}
\ln \left(\mathrm{q}_{\mathrm{e}}-\mathrm{q}_{\mathrm{t}}\right)=\ln \left(\mathrm{q}_{\mathrm{e}}\right)-\mathrm{K}_{1} \mathrm{t} \\
\frac{\mathrm{t}}{\mathrm{q}_{\mathrm{t}}}=\frac{1}{\mathrm{~K}_{2} \mathrm{q}_{\mathrm{e}}^{2}}+\frac{1}{\mathrm{q}_{\mathrm{e}}} \mathrm{t}
\end{gathered}
$$

To explore adsorption kinetics of arsenic on the hybrid beads, pseudo first order and pseudo second order kinetics (Equations (6) and (7)) were also applied, whereas Equation (8) was used to investigate the maximum adsorption.

$$
\mathrm{q}_{\mathrm{e}}=\left(\frac{\mathrm{C}_{\mathrm{i}}-\mathrm{C}_{\mathrm{e}}}{\mathrm{W}}\right) \mathrm{V}
$$

where " $\mathrm{q}_{\mathrm{e}}$ " is equilibrium adsorption of arsenic, " $\mathrm{Ci}$ " and " $\mathrm{Ce}$ " are initial and equilibrium concentration $(\mathrm{mg} / \mathrm{L})$, respectively, " $\mathrm{V}$ " is the volume of solution $(\mathrm{L})$, and " $\mathrm{W}$ " is the weight of dry adsorbent (g).

\section{Results and Discussion}

\subsection{Structural Analysis of Virgin NZVI and Hybrid Beads}

XRD was employed to measure crystallite size and to study the crystal architecture of prepared iron oxide NPs (Figure 2). The lattice spacing was quantified from $2 \theta$ reflection of peaks at $30^{\circ}, 35.1^{\circ}, 44.1^{\circ}, 53.4^{\circ}, 56.9^{\circ}$ and $62.5^{\circ}$, which corresponded to planes 220 , $311,400,422,511$ and 440 , respectively [23]. The peak at $35.1^{\circ}$ could be attributed to the oxidation of trace NZVI during preparation [24]. The absence of an extra peak confirmed the purity of the iron oxide while the solvent (water, ethanol) did not exhibit an effect on the crystal structure of the NPs. The peak pattern of NZVI matched well with database JCPDS file 01-089-0687 for iron oxide nanoparticles [25]. The XRD diffractogram also provided physical and chemical information about iron oxide NPs impregnated into chitosan beads. The diffraction peaks were observed at $2 \theta$ values of $20^{\circ}, 35.1^{\circ}, 43^{\circ}$ and $62^{\circ}$ [26]. These diffraction peaks were reconcilable with database JCPDS file 039-1894, with iron oxide particles having a spinel structure [27]. This confirmed the successful incorporation of iron oxide NPs in chitosan beads. The XRD diffractogram was used for the phase study of the adsorbed material after the arsenic adsorption experiment (Figure 2). Some peaks were detected at $2 \theta$ values of $11^{\circ}$ and $35^{\circ}$, which indicates the adsorption of arsenic in crystalline form [28]. This is in agreement with arsenic XRD values in the database JCPDS file 00-008-0667. These results have confirmed that arsenic was successfully adsorbed onto iron oxide-embedded chitosan beads [29].

\subsection{Functional Group Studies}

IR spectra of NZVI are shown in Figure 3. The typical wide absorption signal at $531 \mathrm{~cm}^{-1}$ is due to vibrational stretching of the iron-oxygen functional moiety, while its shape and intensity indicate the crystalline structure of the magnetite property [30]. The characteristic absorbance at $1041 \mathrm{~cm}^{-1}$ is attributed to the $(C=O)$ vibration, while the signal at $1415 \mathrm{~cm}^{-1}$ is due to the well-ordered vibrational stretching of the unidentate group of carbonates [31]. This can be attributed to the use of the ethylene glycol solvent with minor amounts of polyethylene glycol and sodium acetate. The absorption signals at $1555 \mathrm{~cm}^{-1}$ and $1537 \mathrm{~cm}^{-1}$ were attributed to the vibrational band of COO-Fe and the symmetric stretched band of -COO- bonds, respectively [32,33]. 

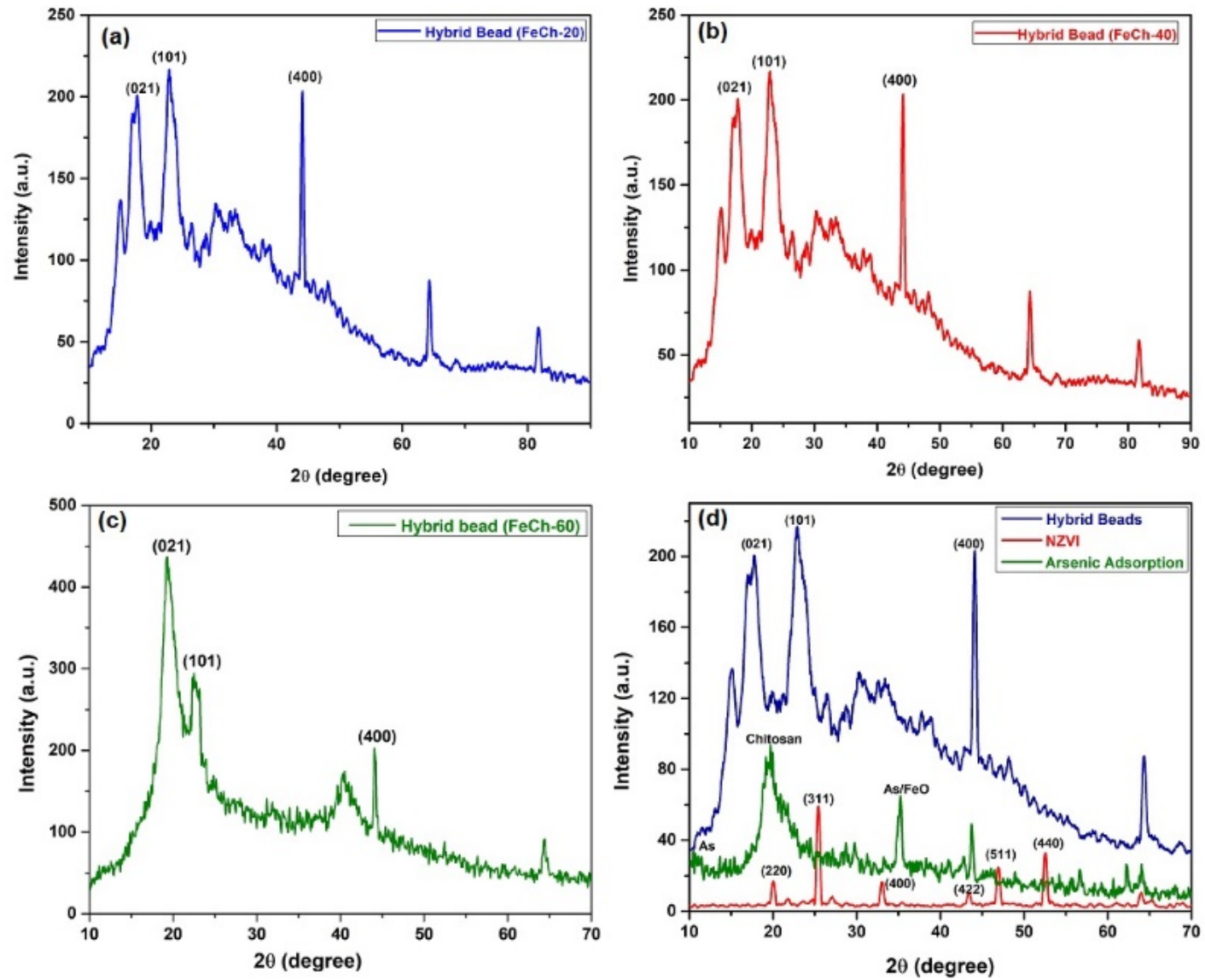

Figure 2. (a) XRD of FeCh-20 hybrid beads, (b) XRD of FeCh-40 hybrid beads sample, (c) XRD of FeCh-60 hybrid beads sample, (d) XRD of NZVI, NPs impregnated chitosan hybrid beads and hybrid beads after arsenic adsorption.

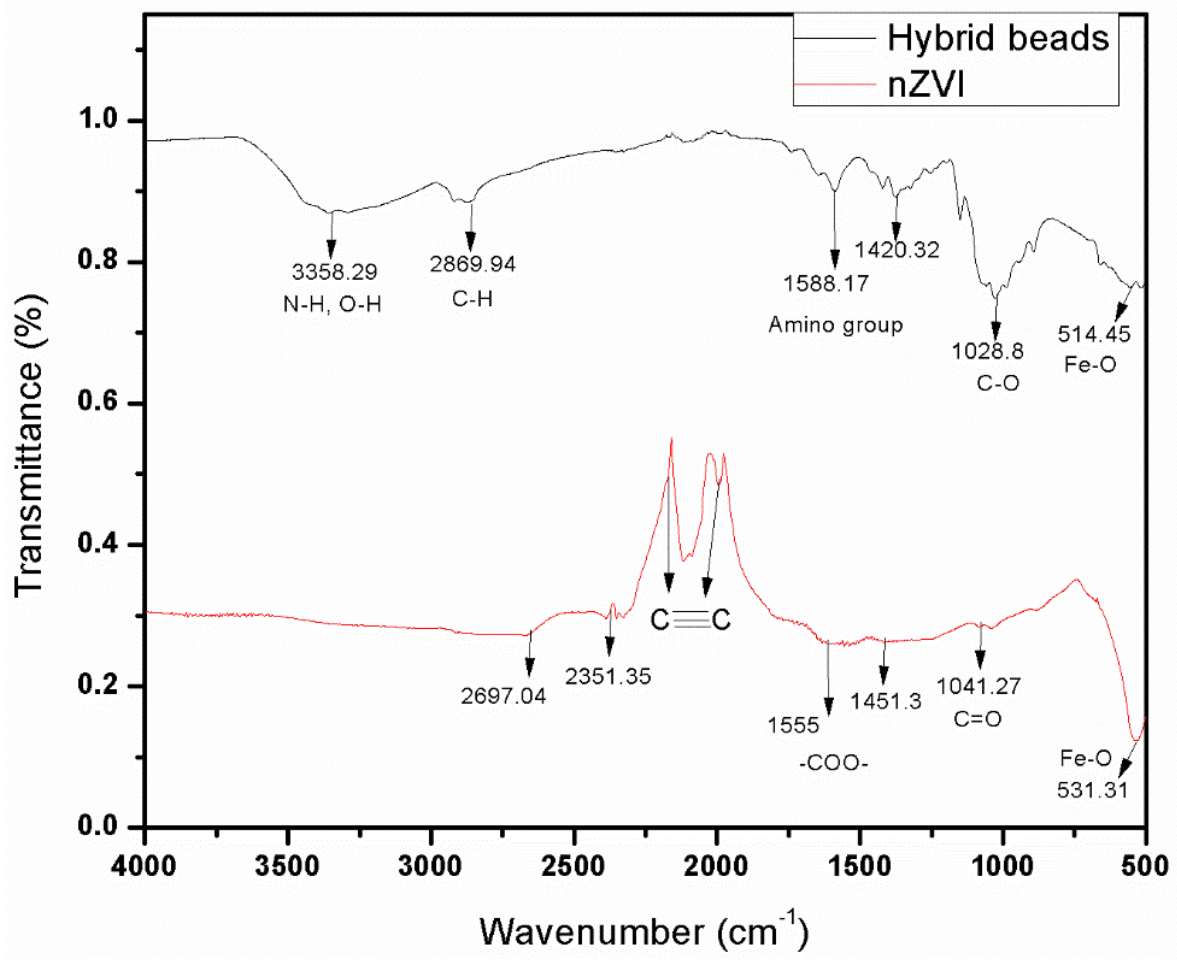

Figure 3. FTIR of NZVI and NPs impregnated chitosan hybrid beads. 
IR spectra of exhausted NZVI-chitosan beads were recorded to understand the mechanism of arsenic adsorption (Figure 3). The characteristic band at $893 \mathrm{~cm}^{-1}$ corresponded to the $\mathrm{Fe}-\mathrm{OH}$ vibration of the akageneite (chloride containing iron hydro oxide) hybrid solution $[34,35]$. The absorption signal at $1375 \mathrm{~cm}^{-1}$ was assigned to the $\mathrm{C}-\mathrm{O}$ of the alcoholic group in chitosan [36], while absorption bands at $1028 \mathrm{~cm}^{-1}$ and $1149 \mathrm{~cm}^{-1}$ corresponded to the $\mathrm{C}-\mathrm{O}$ single bond stretching vibrations in $\mathrm{COC}$ and $\mathrm{CH}_{2} \mathrm{OH}$ categories of the pyranose ring. The absorption at $1588 \mathrm{~cm}^{-1}$ was assigned to the amino group $(\mathrm{N}-\mathrm{H})$ stretching band. This signal was displaced from $1555 \mathrm{~cm}^{-1}$ to $1588 \mathrm{~cm}^{-1}$ after impregnation into chitosan due to the coordination effect [37]. The broad signal at $2869 \mathrm{~cm}^{-1}$ was attributed to the $\mathrm{C}-\mathrm{H}$ vibration stretching of methylene $\left(-\mathrm{CH}_{2}\right)$ and methyl $\left(-\mathrm{CH}_{3}\right)$ groups present in chitosan $[35,38]$. The vibrational signals marked at $3358 \mathrm{~cm}^{-1}$ were due to N-H and O-H vibrational stretching in hybrid material [35,39]. The absorbance at $514 \mathrm{~cm}^{-1}$ and $559 \mathrm{~cm}^{-1}$ was related to the presence of the Fe-O group, attributed to the embedment of iron oxide particles [40].

\subsection{Morphological Analysis of NZVI and Hybrid Beads}

The SEM micrograph of NZVI (Figure 4a) exhibits a homogenous and regular distribution of iron oxide NPs with an average size of $150 \mathrm{~nm}$. The morphology of NPs seems to be an agglomerate of small particles [41,42]. This may be due to a steric effect caused by the interaction of active points on NPs' surface and the magnetic interactions created by single particles [43].The surface analysis of the prepared hybrid beads indicates that NPs were successfully impregnated onto the chitosan. The SEM micrographs show that most of the NPs were embedded onto the chitosan matrix surface [44]. This configuration offers dual benefits of availability of NPs for adsorption and stability of bead shape that facilitates the handling of adsorbent materials in the column bed. SEM results (Figure $4 \mathrm{~b}-\mathrm{d}$ ) of different samples show that the density of iron oxide NPs increased on the bead surface with the increased concentration of NPs during preparation [45].

Studying the surface of iron oxide-impregnated chitosan beads after the arsenic adsorption experiment was also performed using the SEM technique (Figure 4e,f). Distinctive changes were observed in the morphology of beads after adsorption. A multilayered crystal structure of arsenic was found on the surface of the hybrid beads, showing the good adsorption capacity of prepared materials for arsenic pollutants [46].

\subsection{Porosity Studies of Hybrid Beads}

The average pore size and pore diameter $\left(\mathrm{P} / \mathrm{P}_{\mathrm{o}}\right)$ of hybrid beads were measured using the BET technique based on the Barret-Joyner-Halenda (BJH) method (Figure 5). Average pore size and volume in hybrid beads were calculated using Equation (1), giving values of $4.55 \mu \mathrm{m}$ and $1.09 \mathrm{~cm}^{3} / \mathrm{g}$, respectively. The substantial pore size present on the surface of the hybrid beads may have assisted the mass transfer between the beads and arsenic [47]. In compliance with the protocols of Archimedes' rule, the average porosity of the hybrid beads from various samples was estimated as $67.16 \%$ using following equation [22].

\subsection{Surface Wettability Analysis}

The hydrophilic nature of a bead's surface increases its adsorption properties by improving wettability, adhesiveness and high surface energy [48]. The hydrophilic nature of the prepared hybrid beads was determined by contact angle analysis with water. The graph shown in Figure 6 reveals that the sample FeCh- 60 possessed a hydrophobic nature $\left(\theta=85^{\circ}\right)$ due to a relatively lower amount of chitosan, whereas FeCh-20 and FeCh-40 demonstrated maximum surface wettability by presenting contact angles of $53^{\circ}$ and $66^{\circ}$, respectively. Since chitosan is a hydrophilic material owing to $-\mathrm{NH}_{2}$ and $-\mathrm{OH}$ groups, the hydrophilic nature of the hybrid beads was reduced by decreasing the chitosan concentration [49]. Moreover, it is associated with an increase in iron oxide NPs; a greater area of its surface would be occupied by NPs, which would reduce surface wettability. The wetting property 
increased the contact area between the water and the surface of the hybrid beads which, in turn, enhanced the adsorption of arsenic.
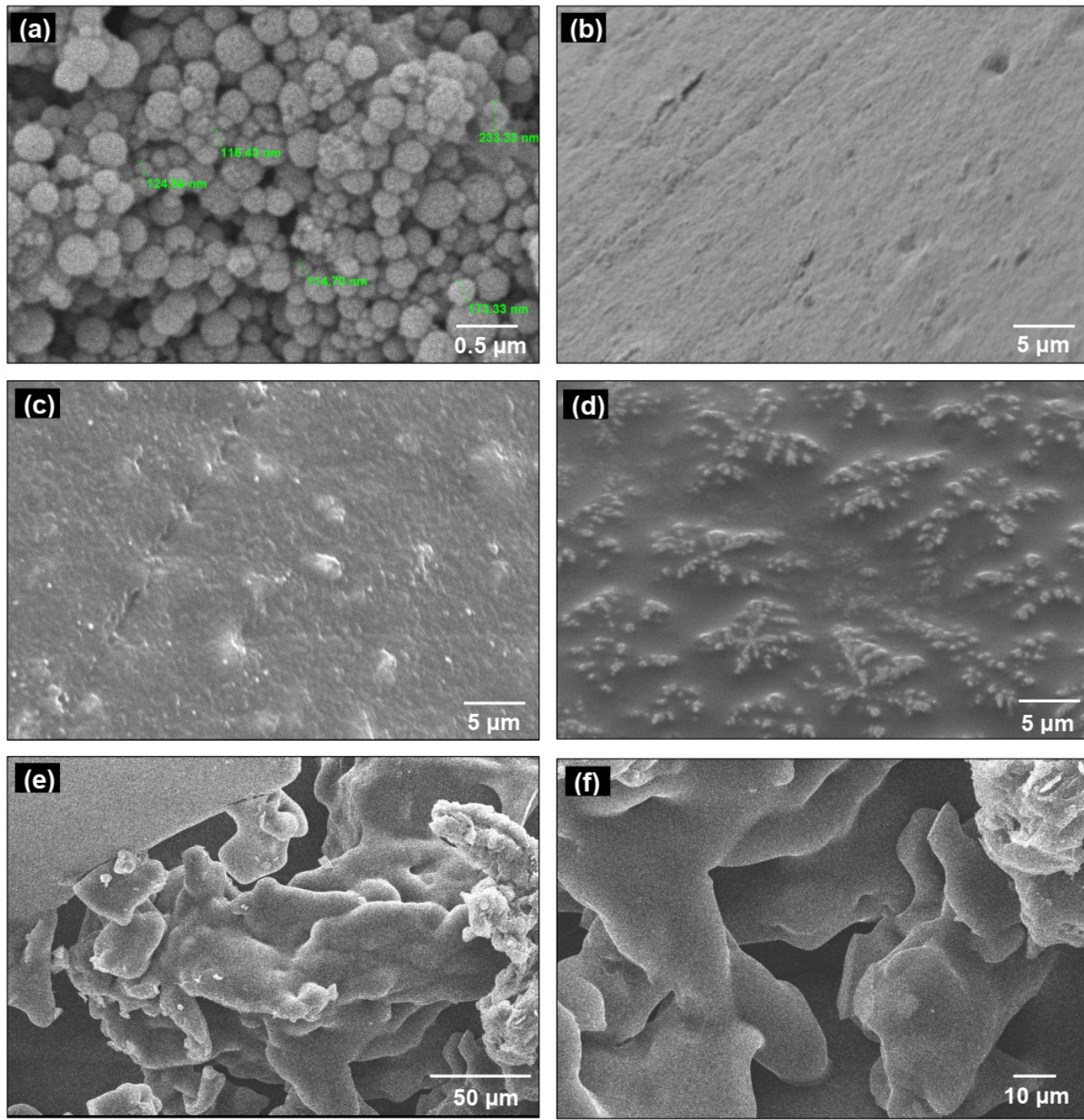

Figure 4. SEM micro images of: (a) NZVI, (b) hybrid bead FeCh-20, (c) hybrid bead (FeCh-40), (d) hybrid bead (FeCh-60), (e) hybrid beads FeCh-20 after arsenic adsorption, and (f) hybrid beads FeCh-40 after arsenic adsorption.

\subsection{Adsorption Efficiency}

An arsenic adsorption mechanism is proposed in Figure 7. The arsenic adsorption capacity of hybrid beads was investigated under varying parameters such as initial concentration of adsorbate, $\mathrm{pH}$ and contact time by applying different isotherm models, as shown in Figure 8. The ion exchange method was a very effective technique for arsenic removal, particularly when ferrous materials were employed as they were able to accommodate arsenic ions in interlayer voids, thus enhancing performance [50]. Initially, the As-O bond broke up via reduction upon adsorption onto the NZVI surface because the transfer of electrons was thermodynamically favored. This reduced arsenic diffusion from the oxide shell interface to the interior of the particle. Reducing agents such as $\mathrm{e}^{-}, \mathrm{H}_{2}$ or $\mathrm{Fe}^{2+}$ were generated from NZVI corrosion in aqueous media. These penetrated through the magnetite layer to attack the arsenic, which formed an Fe-As bond via reduction. According to the literature [51], this may be due to an electron-transfer from $\mathrm{Fe}$ to As, thus producing an FeAs bond and coagulate. At neutral $\mathrm{pH}$, arsenic mainly exists in the form of $\mathrm{H}_{2} \mathrm{AsO}_{4}{ }^{-}$ions. The NZVI nanoparticles embedded within the complex structure of chitosan enhanced its stability and offered extra adsorbing active points for the arsenic [52]. The free amine 
group present in chitosan could then be protonated in aqueous media. $\mathrm{AsO}_{4}{ }^{-3}$ anions were mostly bonded to amino groups of chitosan, which may form $\mathrm{R}_{-} \mathrm{NH}_{3}{ }^{+}$after protonation with arsenate ions. The adsorption capacity of prepared materials is represented in Figure 8 a. The highest adsorption capacity was measured at $18 \mathrm{mg} / \mathrm{g}$ for FeCh-40 owing to its maximum porosity and the hydrophilic property of its beads. Adsorption capacities of $14 \mathrm{mg} / \mathrm{g}$ and $16.7 \mathrm{mg} / \mathrm{g}$ were measured for FeCh-20 and FeCh-60, respectively. Moreover, FeCh-40 demonstrated the maximum removal of arsenic at $81 \%$, as determined by Equation (2). The arsenic adsorption capacity $\left(\mathrm{q}_{\mathrm{e}}\right)$ was also estimated by another relation given in Equation (3).

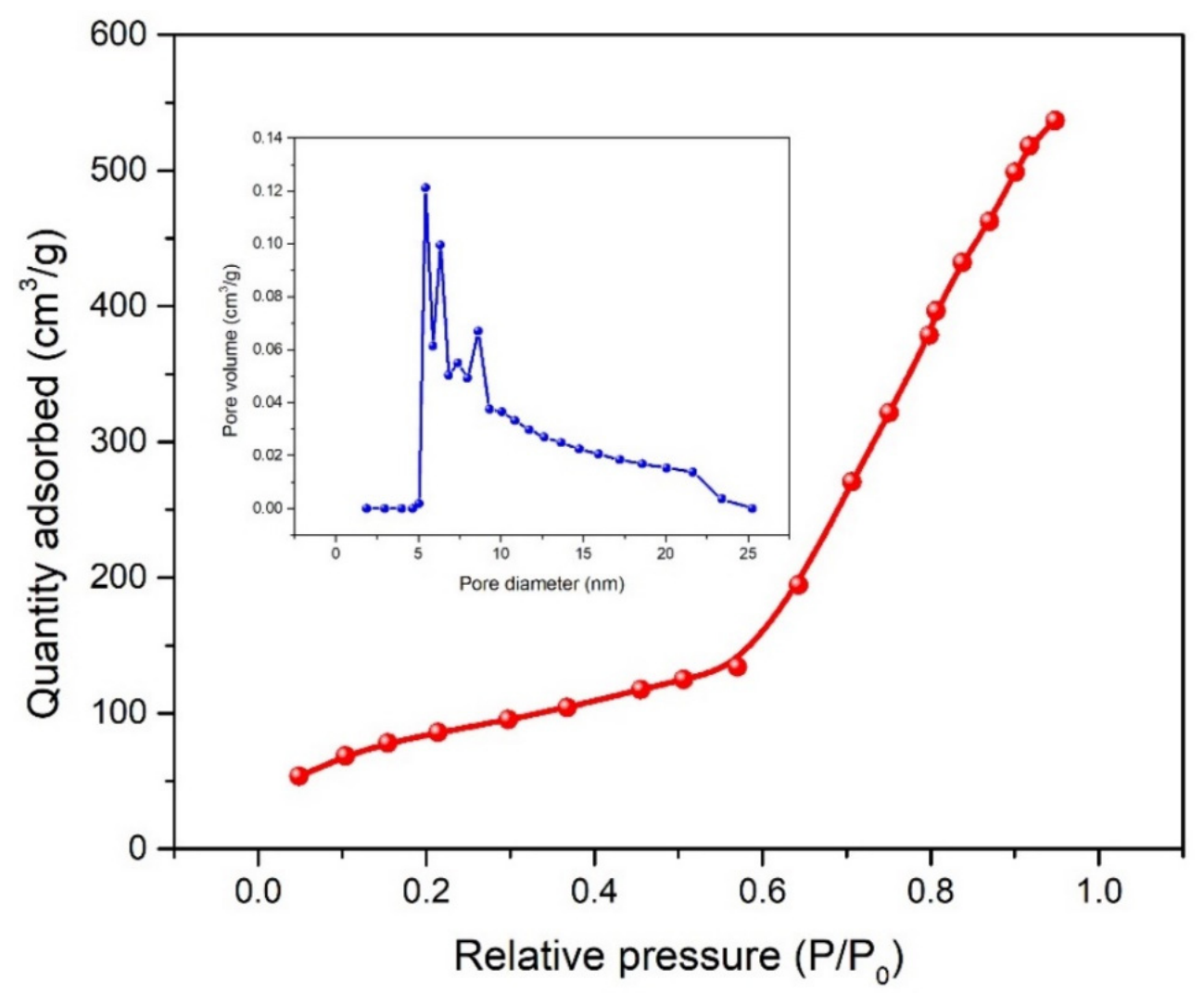

Figure 5. $\mathrm{N}_{2}$ adsorption-desorption isotherms and BJH pore diameter distribution in hybrid beads.

\subsubsection{Effect of Arsenic Initial Concentration}

The batch processes for the treatment of arsenic in water were performed to estimate the arsenic adsorption capability of the hybrid beads, i.e., FeCh-20, FeCh- 40 and FeCh60. An arsenic solution was treated with $1.0 \mathrm{~g}$ of hybrid beads, and the arsenic initial concentration was varied within a $10-40 \mathrm{ppm}$ range in an Erlenmeyer flask with continuous shaking at $150 \mathrm{rpm}$. Samples were evacuated at a constant time period of $10 \mathrm{~h}$, while a neutral $\mathrm{pH}$ value was maintained to study the adsorption isotherm (Figure 8). The hybrid material $\mathrm{FeCh}-40$ produced the best arsenic adsorption capacity values in comparison to some other adsorbents reported in the literature (Table 1). From these results, it is evident that the prepared hybrid materials performed excellently to remove arsenic contamination from water, achieving the standard set by WHO $(10 \mu \mathrm{g} / \mathrm{L})$.

The process of adsorption has also been expressed by Langmuir and Freundlich relations (Equations (3) and (4)) in Figure 8c,d. According to the Langmuir isotherm, the value of $Q_{\max }$ is $4.564 \mathrm{mg} / \mathrm{g}$ and $\mathrm{K}_{\mathrm{L}}$ is $1.0741 / \mathrm{mg}$. The regression coefficient $\left(\mathrm{R}^{2}\right)$ values of the Langmuir and Freundlich isotherms were 0.9951 and 0.98 , respectively. These values have demonstrated that the Langmuir isotherm is the best fitted and that the process of adsorption was chemisorption on a homogenous surface [53]. 


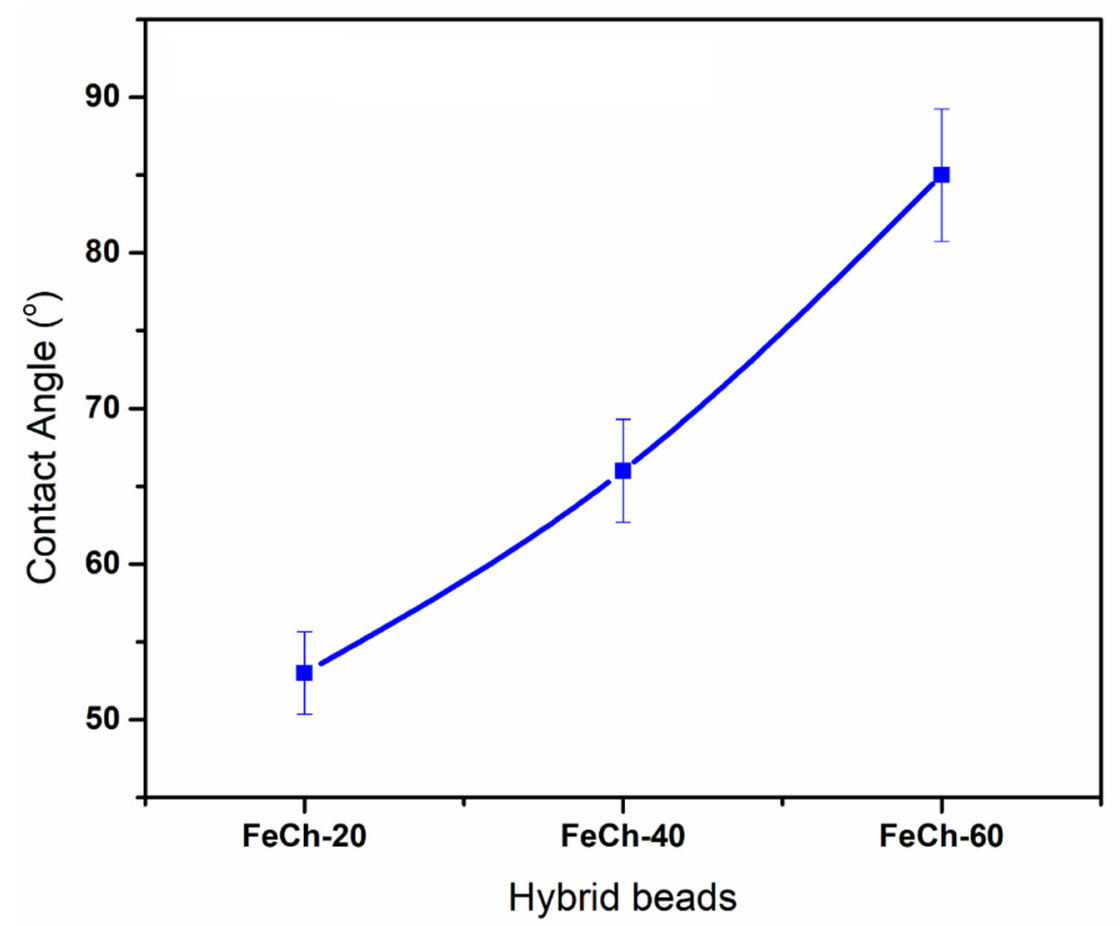

Figure 6. Contact angle of different hybrid beads samples: FeCh-20, FeCh-40 and FeCh-60.
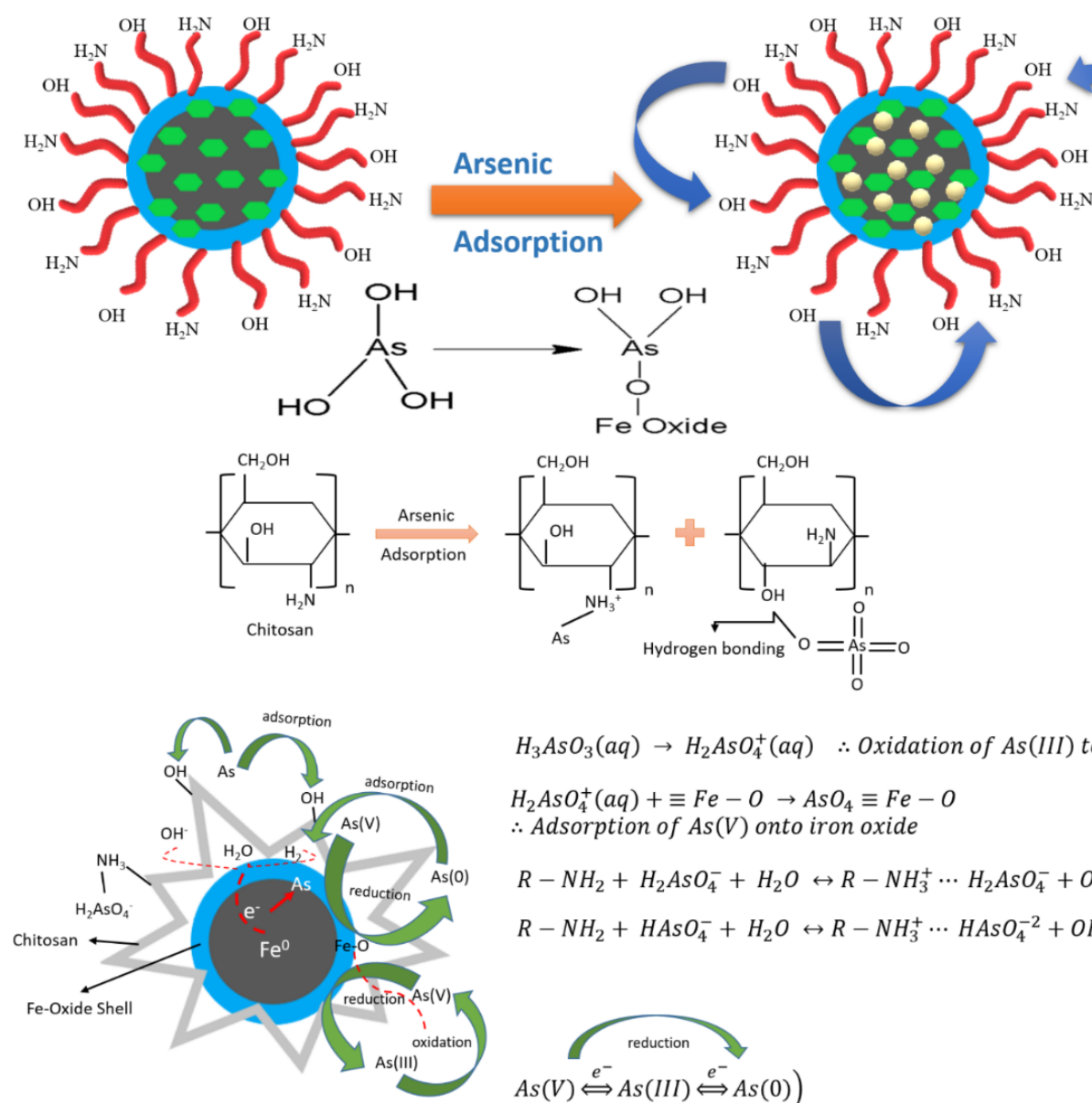

$\mathrm{H}_{3} \mathrm{AsO}_{3}(\mathrm{aq}) \rightarrow \mathrm{H}_{2} \mathrm{AsO}_{4}^{+}(\mathrm{aq}) \quad \therefore$ Oxidation of $\mathrm{As}(\mathrm{III})$ to $\mathrm{As}(\mathrm{V})$

$\mathrm{H}_{2} \mathrm{AsO}_{4}^{+}(a q)+\equiv \mathrm{Fe}-\mathrm{O} \rightarrow \mathrm{AsO}_{4} \equiv \mathrm{Fe}-\mathrm{O}$

$\therefore$ Adsorption of $A s(V)$ onto iron oxide

$\mathrm{R}-\mathrm{NH}_{2}+\mathrm{H}_{2} \mathrm{AsO}_{4}^{-}+\mathrm{H}_{2} \mathrm{O} \leftrightarrow \mathrm{R}-\mathrm{NH}_{3}^{+} \cdots \mathrm{H}_{2} \mathrm{AsO}_{4}^{-}+\mathrm{OH}^{-}$

$\mathrm{R}-\mathrm{NH}_{2}+\mathrm{HAsO}_{4}^{-}+\mathrm{H}_{2} \mathrm{O} \leftrightarrow \mathrm{R}-\mathrm{NH}_{3}^{+} \cdots \mathrm{HAsO}_{4}^{-2}+\mathrm{OH}^{-}$

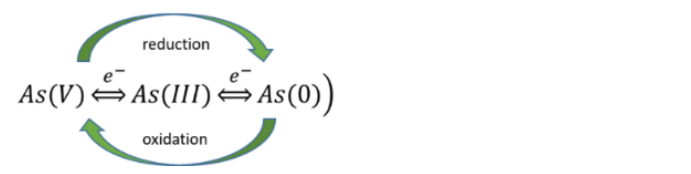

Figure 7. Illustration of arsenic adsorption scheme onto the surface of hybrid beads. 

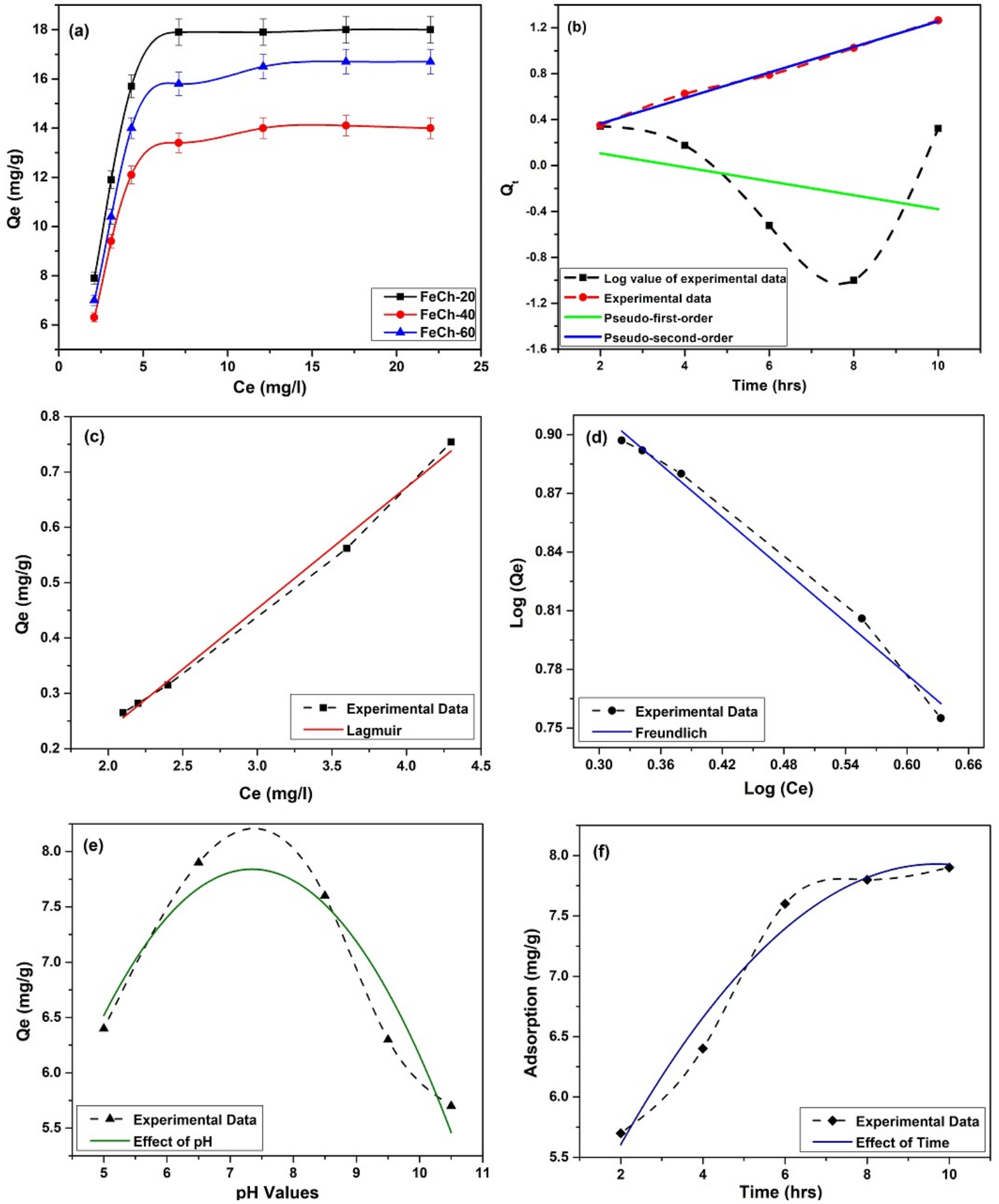

Figure 8. (a) Adsorption capacity of FeCh-20, FeCh-40 and FeCh-60 beads, (b) Pseudo first order and Pseudo second order kinetic model for arsenic adsorption on FeCH-40 beads, (c) Langmuir Model, (d) Freundlich Model, (e) Effect of pH value and (f) Effect of contact period. 
Table 1. Comparison of adsorption values of prepared hybrid beads with other works reported in the literature.

\begin{tabular}{llll}
\hline Adsorbent & Qe (mg/g) & pH & Reference \\
\hline Hybrid NZVI-chitosan beads (FeCh-40) & 18 & $6.6-7.3$ & Present work \\
Lateritic soil & 2 & 7 & {$[54]$} \\
Concrete/maghemite nanocomposites & 11.12 & 5 & {$[55]$} \\
Granulated iron hydroxide & 18 & 7 & {$[56]$} \\
Goethite modified (GT@DAS/TOES) & 7.78 & 6 & {$[55]$} \\
Chitosan goethite bio-nanocomposite (CGB) & 11.3 & $5-6$ & {$[57]$} \\
Granular ferric hydroxide (GFH) & 8 & - & {$[58]$} \\
Iron oxide coated sponge & 4.5 & $6.5-7.3$ & {$[59]$} \\
TiO 2 -impregnated chitosan beads & 2.1 & $9.2-7.7$ & {$[5]$} \\
\hline
\end{tabular}

\subsubsection{Adsorption Kinetics}

In this study, a kinetic test of arsenic adsorption onto the surface of sorbent was also carried out for the adsorption rate measurement according to previous literature [7]. Figure $8 \mathrm{~b}$ indicates the kinetics of arsenic removal from water with $1 \mathrm{~g} / \mathrm{L} \mathrm{FeCh}-40$ sorbent under normal conditions. The kinetic curve has three major regions: initially, the adsorbate rapidly adsorbed onto the surface of the adsorbent; this gradual decreased until, finally, it became saturated when a constant mass was achieved due to maximum adsorption. To explore the adsorption kinetics of arsenic on the hybrid beads, pseudo first order and pseudo second order kinetics (Equations (6) and (7)) were also applied [60]. The value of regression $\left(R^{2}\right) 0.995$ shows that this adsorption process obeys the pseudo second order model. This predicts the performance over a complete range of studies, assists sustainability and supports the assumptions of the model that the process of adsorption occurred because of chemisorption [7].

\subsubsection{Effect of TIME and $\mathrm{pH}$ on Arsenic Adsorption}

The contact time required to attain an adsorption equilibrium between the arsenic solution and the hybrid beads was also investigated (Figure 8f). It is made evident by employment of Equation (8) that maximum adsorption $\left(\mathrm{q}_{\mathrm{e}}\right)$ onto the surface of the beads was attained in $10 \mathrm{~h}$. The initial adsorption rate was very fast because, in the beginning, there was a large number of active points on the surface as well as less resistance for mass transfer on the surface [61].

$\mathrm{pH}$ was a significant parameter that affected the adsorption properties of the beads ${ }^{\prime}$ surface. The most appropriate $\mathrm{pH}$ condition was estimated as follows: by maintaining the $\mathrm{pH}$ of the arsenic solution during the adsorption experiment, while keeping the initial concentration of arsenic constant at $10 \mathrm{mg} / \mathrm{L}$ (Figure 8e). However, low $\mathrm{pH}$ conditions were not applied because chitosan polymer is unstable in acid environments [60]. According to results acquired by the use of Equation (8), the maximum arsenic adsorption on the beads' surface was measured within $\mathrm{pH}$ range 6-8. Because in aerobic water, arsenic exists in $\mathrm{H}_{3} \mathrm{AsO}_{4}$ form, it is dissociated into $\mathrm{HAsO}_{4}{ }^{2-}$ and $\mathrm{H}_{2} \mathrm{AsO}_{4}{ }^{-}$ionic species in aqueous solution in the $\mathrm{pH}$ range 6-8 [62]. This would be favorable for the process of adsorption due to electrostatic attraction, assisting ligand interchange and protonation on the surface of the adsorbent $[48,63]$. However, with the increase in the $\mathrm{pH}$ of the test solution, negatively charged sites on the surface of the sorbent also increased, which diminished the rate of adsorption because of electrostatic repulsion. Hence, these hybrid beads demonstrated a maximum performance of arsenic adsorption at neutral $\mathrm{pH}$, which is highly applicable for the treatment of drinking water.

\section{Conclusions}

Novel hybrid beads of chitosan-functionalized zero valent iron oxide were synthesized by varying concentrations of chitosan and iron oxide. These prepared materials were characterized by FTIR, XRD, SEM and BET techniques. The study showed that a maximum of 
$81 \%$ removal of arsenic was achieved within $10 \mathrm{~h}$ at neutral $\mathrm{pH}$ under optimum conditions of adsorption by a FeCh- 40 hybrid bead sample. The adsorption behavior was satisfactorily illustrated through Langmuir and Freundlich models, while the adsorption mechanism was studied by pseudo first order and pseudo second order kinetics relations. Equilibrium results have recognized the best fitted models as being the pseudo second order, with the correlation coefficient 0.995 , and the Langmuir isotherm model, with regression coefficient 0.99 , while homogenous and monolayer adsorption were identified as the prevailing adsorption mechanism. In this study, the highest arsenic adsorption capacity was achieved at $18 \mathrm{mg}$ arsenic per $\mathrm{g}$ of $\mathrm{FeCh}-40$ adsorbent, whereas $11.2 \mathrm{mg}$ arsenic elimination was reported by maghemite nanocomposites in the literature.

Author Contributions: M.F.A. carried out the experimental work. N.M.A. is the principal investigator of the project and led the project overall. M.A.A. helped to analyze the adsorption data. A.M., A.U.K., R.S. and S.Z. edited the manuscript and supervised experimental work. N.A.K. and M.A.Q. assisted in the design of experiments. H.R. helped to perform the arsenic removal experiment and analyses. H.Q. helped in the formatting of the manuscript. All authors have read and agreed to the published version of the manuscript.

Funding: This research work has not received any external funding.

Institutional Review Board Statement: Not applicable.

Informed Consent Statement: Not applicable.

Data Availability Statement: All the data is provided in this article.

Acknowledgments: All authors are grateful to the NUST Research Directorate for financial support. The corresponding author has acknowledged funding from HEC-NRPU through Project No. 6020.

Conflicts of Interest: The authors declare no conflict of interest.

\section{References}

1. Dotto, G.L.; McKay, G. Current scenario and challenges in adsorption for water treatment. J. Environ. Chem. Eng. 2020, 8, 103988. [CrossRef]

2. Ociński, D.; Mazur, P. Highly efficient arsenic sorbent based on residual from water deironing-Sorption mechanisms and column studies. J. Hazard. Mater. 2020, 382, 121062. [CrossRef]

3. Moghaddam, S.T.; Naimi-Jamal, M.R.; Rohlwing, A.; Hussein, F.B.; Abu-Zahra, N. High Removal Capacity of Arsenic from Drinking Water Using Modified Magnetic Polyurethane Foam Nanocomposites. J. Polym. Environ. 2019, 27, 1497-1504. [CrossRef]

4. Wen, Z.; Lu, J.; Zhang, Y.; Cheng, G.; Huang, S.; Chen, J.; Xu, R.; Ming, Y.-A.; Wang, Y.; Chen, R. Facile inverse micelle fabrication of magnetic ordered mesoporous iron cerium bimetal oxides with excellent performance for arsenic removal from water. J. Hazard. Mater. 2020, 383, 121172. [CrossRef]

5. Miller, S.M.; Zimmerman, J.B. Novel, bio-based, photoactive arsenic sorbent: $\mathrm{TiO}_{2}$-impregnated chitosan bead. Water Res. 2010, 44, 5722-5729. [CrossRef] [PubMed]

6. Wei, Y.; Liu, H.; Liu, C.; Luo, S.; Liu, Y.; Yu, X.; Ma, J.; Yin, K.; Feng, H. Fast and efficient removal of As (III) from water by $\mathrm{CuFe}_{2} \mathrm{O}_{4}$ with peroxymonosulfate: Effects of oxidation and adsorption. Water Res. 2019, 150, 182-190. [CrossRef] [PubMed]

7. López-Guzmán, M.; Alarcón-Herrera, M.; Irigoyen-Campuzano, J.; Torres-Castañón, L.; Reynoso-Cuevas, L. Simultaneous removal of fluoride and arsenic from well water by electrocoagulation. Sci. Total Environ. 2019, 678, 181-187. [CrossRef] [PubMed]

8. Habib, Z.; Khan, S.J.; Ahmad, N.M.; Shahzad, H.M.A.; Jamal, Y.; Hashmi, I. Antibacterial behaviour of surface modified composite polyamide nanofiltration (NF) membrane by immobilizing Ag-doped $\mathrm{TiO}_{2}$ nanoparticles. Environ. Technol. 2020, 41, $3657-3669$. [CrossRef] [PubMed]

9. Kumar, M.; RaoT, S.; Isloor, A.M.; Ibrahim, G.S.; Inamuddin; Ismail, N.; Ismail, A.F.; Asiri, A.M. Use of cellulose acetate/polyphenylsulfone derivatives to fabricate ultrafiltration hollow fiber membranes for the removal of arsenic from drinking water. Int. J. Biol. Macromol. 2019, 129, 715-727. [CrossRef]

10. Shadbahr, J.; Husain, T. Affordable and efficient adsorbent for arsenic removal from rural water supply systems in Newfoundland. Sci. Total Environ. 2019, 660, 158-168. [CrossRef]

11. Torasso, N.; Vergara-Rubio, A.; Rivas-Rojas, P.; Huck-Iriart, C.; Larrañaga, A.; Fernández-Cirelli, A.; Cerveny, S.; Goyanes, S. Enhancing arsenic adsorption via excellent dispersion of iron oxide nanoparticles inside poly (vinyl alcohol) nanofibers. J. Environ. Chem. Eng. 2021, 9, 104664. [CrossRef]

12. Saif, S.; Tahir, A.; Asim, T.; Chen, Y.; Adil, S.F. Polymeric Nanocomposites of Iron-Oxide Nanoparticles (IONPs) Synthesized Using Terminalia chebula Leaf Extract for Enhanced Adsorption of Arsenic (V) from Water. Colloids Interfaces 2019, 3, 17. [CrossRef] 
13. Mukherjee, T.; Ghosh, G.; Mukherjee, R.; Das, T.K. Study of arsenic (III) removal by monolayer protected silver nanoadsorbent and its execution on prokaryotic system. J. Environ. Manag. 2019, 244, 440-452. [CrossRef]

14. Malwal, D.; Gopinath, P. Silica stabilized magnetic-chitosan beads for removal of arsenic from water. Colloid Interface Sci. Commun. 2017, 19, 14-19. [CrossRef]

15. Eisazadeh, H. Removal of arsenic in water using polypyrrole and its composites. Appl. Sci. J. 2008, 3, 10-13.

16. Alabaraoye, E.; Achilonu, M.; Hester, R. Biopolymer (Chitin) from various marine seashell wastes: Isolation and characterization. J. Polym. Environ. 2018, 26, 2207-2218. [CrossRef]

17. Muthukumar, T.; Aravinthan, A.; Lakshmi, K.; Venkatesan, R.; Vedaprakash, L.; Doble, M. Fouling and stability of polymers and composites in marine environment. Int. Biodeterior. Biodegrad. 2011, 65, 276-284. [CrossRef]

18. Tsagdi, A.; Druvari, D.; Panagiotaras, D.; Avramidis, P.; Bekiari, V.; Kallitsis, J.K. Polymeric Coatings Based on Water-Soluble Trimethylammonium Copolymers for Antifouling Applications. Molecules 2020, 25, 1678. [CrossRef] [PubMed]

19. Mishra, T.; Mahato, D.K. A comparative study on enhanced arsenic (V) and arsenic (III) removal by iron oxide and manganese oxide pillared clays from ground water. J. Environ. Chem. Eng. 2016, 4, 1224-1230. [CrossRef]

20. Joshi, S.; Sharma, M.; Kumari, A.; Shrestha, S.; Shrestha, B. Arsenic Removal from Water by Adsorption onto Iron Oxide/NanoPorous Carbon Magnetic Composite. Appl. Sci. 2019, 9, 3732. [CrossRef]

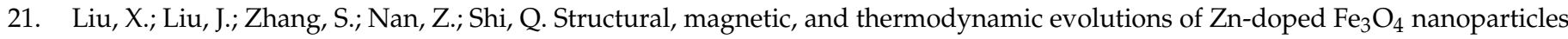
synthesized using a one-step solvothermal method. J. Phys. Chem. C 2016, 120, 1328-1341. [CrossRef]

22. Zu, Y.; Zhang, Y.; Zhao, X.; Shan, C.; Zu, S.; Wang, K.; Li, Y.; Ge, Y. Preparation and characterization of chitosan-polyvinyl alcohol blend hydrogels for the controlled release of nano-insulin. Int. J. Biol. Macromol. 2012, 50, 82-87. [CrossRef]

23. Liu, A.; Liu, J.; Zhang, W.-x. Transformation and composition evolution of nanoscale zero valent iron (nZVI) synthesized by borohydride reduction in static water. Chemosphere 2015, 119, 1068-1074. [CrossRef]

24. Rahmani, A.; Ghafari, H.R.; Samadi, M.T.; Zarabi, M. Synthesis of zero valent iron nanoparticles (nzvi) and its efficiency in arsenic removal from aqueous solutions. Water Wastewater 2011, 1, 35-41.

25. Kesavan, S.K.; Azad, A.-M. Conversion of steel mill waste into nanoscale zerovalent iron (nZVI) particles for hydrogen generation via metal-steam reforming. Int. J. Hydrogen Energy 2008, 33, 1232-1242. [CrossRef]

26. Pincus, L.N.; Melnikov, F.; Yamani, J.S.; Zimmerman, J.B. Multifunctional photoactive and selective adsorbent for arsenite and arsenate: Evaluation of nano titanium dioxide-enabled chitosan cross-linked with copper. J. Hazard. Mater. 2018, 358, 145-154. [CrossRef]

27. Kumar, V.; Jahan, F.; Raghuwanshi, S.; Mahajan, R.V.; Saxena, R.K. Immobilization of Rhizopus oryzae lipase on magnetic $\mathrm{Fe}_{3} \mathrm{O}_{4}$-chitosan beads and its potential in phenolic acids ester synthesis. Biotechnol. Bioprocess Eng. 2013, 18, 787-795. [CrossRef]

28. Wang, W.; Zheng, L.; Lu, F.; Hong, R.; Chen, M.Z.; Zhuang, L. Facile synthesis and characterization of magnetochromatic $\mathrm{Fe}_{3} \mathrm{O}_{4}$ nanoparticles. AIP Adv. 2017, 7, 056317. [CrossRef]

29. Mandal, S.; Sahu, M.K.; Patel, R.K. Adsorption studies of arsenic (III) removal from water by zirconium polyacrylamide hybrid material (ZrPACM-43). Water Resour. Ind. 2013, 4, 51-67. [CrossRef]

30. Srivastava, V.; Singh, P.; Weng, C.; Sharma, Y. Economically viable synthesis of $\mathrm{Fe}_{3} \mathrm{O}_{4}$ nanoparticles and their characterization. Pol. J. Chem. Technol. 2011, 13, 1-5. [CrossRef]

31. Imtiaz, A.; Farrukh, M.A.; Khaleeq-ur-Rahman, M.; Adnan, R. Micelle-assisted synthesis of $\mathrm{Al}_{2} \mathrm{O}_{3} \mathrm{CaO}$ nanocatalyst: Optical properties and their applications in photodegradation of 2, 4, 6-trinitrophenol. Sci. World J. 2013, 2013, 1-11. [CrossRef] [PubMed]

32. Wei, Y.; Han, B.; Hu, X.; Lin, Y.; Wang, X.; Deng, X. Synthesis of $\mathrm{Fe}_{3} \mathrm{O}_{4}$ nanoparticles and their magnetic properties. Procedia Eng. 2012, 27, 632-637. [CrossRef]

33. Yang, K.; Peng, H.; Wen, Y.; Li, N. Re-examination of characteristic FTIR spectrum of secondary layer in bilayer oleic acid-coated $\mathrm{Fe}_{3} \mathrm{O}_{4}$ nanoparticles. Appl. Surf. Sci. 2010, 256, 3093-3097. [CrossRef]

34. Gotić, M.; Musić, S. Mössbauer, FT-IR and FE SEM investigation of iron oxides precipitated from FeSO 4 solutions. J. Mol. Struct. 2007, 834, 445-453. [CrossRef]

35. Lu, J.; Xu, K.; Yang, J.; Hao, Y.; Cheng, F. Nano iron oxide impregnated in chitosan bead as a highly efficient sorbent for Cr (VI) removal from water. Carbohydr. Polym. 2017, 173, 28-36. [CrossRef]

36. Gällstedt, M.; Hedenqvist, M.S. Oxygen and water barrier properties of coated whey protein and chitosan films. J. Polym. Environ. 2002, 10, 1-4. [CrossRef]

37. Dong, C.; Chen, W.; Liu, C. Preparation of novel magnetic chitosan nanoparticle and its application for removal of humic acid from aqueous solution. Appl. Surf. Sci. 2014, 292, 1067-1076. [CrossRef]

38. Elwakeel, K.Z.; Guibal, E. Arsenic (V) sorption using chitosan/Cu (OH) 2 and chitosan/CuO composite sorbents. Carbohydr. Polym. 2015, 134, 190-204. [CrossRef]

39. Hernández, R.B.; Franco, A.P.; Yola, O.R.; Lopez-Delgado, A.; Felcman, J.; Recio, M.A.L.; Mercê, A.L.R. Coordination study of chitosan and Fe3+. J. Mol. Struct. 2008, 877, 89-99. [CrossRef]

40. He, R.; Peng, Z.; Lyu, H.; Huang, H.; Nan, Q.; Tang, J. Synthesis and characterization of an iron-impregnated biochar for aqueous arsenic removal. Sci. Total Environ. 2018, 612, 1177-1186. [CrossRef]

41. Shen, J.; Zhu, Y.; Zhou, K.; Yang, X.; Li, C. Tailored anisotropic magnetic conductive film assembled from graphene-encapsulated multifunctional magnetic composite microspheres. J. Mater. Chem. 2012, 22, 545-550. [CrossRef] 
42. Yang, X.; Chen, W.; Huang, J.; Zhou, Y.; Zhu, Y.; Li, C. Rapid degradation of methylene blue in a novel heterogeneous Fe $\mathrm{O}_{4} @$ rGO@ $\mathrm{TiO}_{2}$-catalyzed photo-Fenton system. Sci. Rep. 2015, 5, 10632. [CrossRef]

43. de JesúsRuíz-Baltazar, Á.; Reyes-López, S.Y.; Mondragón-Sánchez, M.D.L.; Robles-Cortés, A.I.; Pérez, R. Eco-friendly synthesis of $\mathrm{Fe}_{3} \mathrm{O}_{4}$ nanoparticles: Evaluation of their catalytic activity in methylene blue degradation by kinetic adsorption models. Results Phys. 2019, 12, 989-995. [CrossRef]

44. Suyatma, N.E.; Copinet, A.; Tighzert, L.; Coma, V. Mechanical and barrier properties of biodegradable films made from chitosan and poly (lactic acid) blends. J. Polym. Environ. 2004, 12, 1-6. [CrossRef]

45. Chen, B.; Zhao, H.; Chen, S.; Long, F.; Huang, B.; Yang, B.; Pan, X. A magnetically recyclable chitosan composite adsorbent functionalized with EDTA for simultaneous capture of anionic dye and heavy metals in complex wastewater. Chem. Eng. J. 2019, 356, 69-80. [CrossRef]

46. Irem, S.; Islam, E.; Mahmood Khan, Q.; Anwar ul Haq, M.; Jamal Hashmat, A. Adsorption of arsenic from drinking water using natural orange waste: Kinetics and fluidized bed column studies. Water Sci. Technol. Water Supply 2017, 17, 1149-1159. [CrossRef]

47. Sikdera, M.T.; Kubotad, R.; Akterd, M.; Rahmand, M.M.; Hossaind, K.F.B.; Rahamand, M.S.; Banikd, S.; Hosokawae, T.; Saitob, T.; Kurasakia, M. Adsorption mechanism of Cu (II) in water environment using chitosan-nano zero valent iron-activated carbon composite beads. Desalination Water Treat. 2019, 145, 202-210. [CrossRef]

48. Halder, J.N.; Islam, M.N. Water pollution and its impact on the human health. J. Environ. Hum. 2015, 2, 36-46. [CrossRef]

49. Gohari, R.J.; Lau, W.J.; Halakoo, E.; Ismail, A.F.; Korminouri, F.; Matsuura, T.; Gohari, M.S.J.; Chowdhury, M.N.K. Arsenate removal from contaminated water by a highly adsorptive nanocomposite ultrafiltration membrane. N. J. Chem. 2015, 39, 8263-8272. [CrossRef]

50. Tuček, J.í.; Prucek, R.; Kolařík, J.; Zoppellaro, G.; Petr, M.; Filip, J.; Sharma, V.K.; Zbořil, R. Zero-valent iron nanoparticles reduce arsenites and arsenates to As (0) firmly embedded in Core-Shell superstructure: Challenging strategy of arsenic treatment under anoxic conditions. ACS Sustain. Chem. Eng. 2017, 5, 3027-3038. [CrossRef]

51. Jing, C.; Korfiatis, G.P.; Meng, X. Immobilization mechanisms of arsenate in iron hydroxide sludge stabilized with cement. Environ. Sci. Technol. 2003, 37, 5050-5056. [CrossRef]

52. Hao, L.; Liu, M.; Wang, N.; Li, G. A critical review on arsenic removal from water using iron-based adsorbents. RSC Adv. 2018, 8, 39545-39560. [CrossRef]

53. White, R.L.; White, C.M.; Turgut, H.; Massoud, A.; Tian, Z.R. Comparative studies on copper adsorption by graphene oxide and functionalized graphene oxide nanoparticles. J. Taiwan Inst. Chem. Eng. 2018, 85, 18-28. [CrossRef]

54. Boglione, R.; Griffa, C.; Panigatti, M.C.; Keller, S.; Schierano, M.C.; Asforno, M. Arsenic adsorption by soil from Misiones province, Argentina. Environ. Technol. Innov. 2019, 13, 30-36. [CrossRef]

55. Hernández-Flores, H.; Pariona, N.; Herrera-Trejo, M.; Hdz-García, H.M.; Mtz-Enriquez, A.I. Concrete/maghemite nanocomposites as novel adsorbents for arsenic removal. J. Mol. Struct. 2018, 1171, 9-16. [CrossRef]

56. Lescano, M.R.; Passalía, C.; Zalazar, C.S.; Brandi, R.J. Arsenic sorption onto titanium dioxide, granular ferric hydroxide and activated alumina: Batch and dynamic studies. J. Environ. Sci. Health Part A 2015, 50, 424-431. [CrossRef]

57. He, J.; Bardelli, F.; Gehin, A.; Silvester, E.; Charlet, L. Novel chitosan goethite bionanocomposite beads for arsenic remediation. Water Res. 2016, 101, 1-9. [CrossRef]

58. Badruzzaman, M.; Westerhoff, P.; Knappe, D.R. Intraparticle diffusion and adsorption of arsenate onto granular ferric hydroxide (GFH). Water Res. 2004, 38, 4002-4012. [CrossRef]

59. Nguyen, T.V.; Vigneswaran, S.; Ngo, H.H.; Kandasamy, J. Arsenic removal by iron oxide coated sponge: Experimental performance and mathematical models. J. Hazard. Mater. 2010, 182, 723-729. [CrossRef]

60. Kwon, O.-H.; Kim, J.-O.; Cho, D.-W.; Kumar, R.; Baek, S.H.; Kurade, M.B.; Jeon, B.-H. Adsorption of As (III), As (V) and Cu (II) on zirconium oxide immobilized alginate beads in aqueous phase. Chemosphere 2016, 160, 126-133. [CrossRef]

61. Liu, B.; Wang, D.; Li, H.; Xu, Y.; Zhang, L. As (III) removal from aqueous solution using $\alpha-\mathrm{Fe}_{2} \mathrm{O}_{3}$ impregnated chitosan beads with As (III) as imprinted ions. Desalination 2011, 272, 286-292. [CrossRef]

62. Wei, Z.; Wang, Z.; Yan, J.; Liu, Y.; Wu, Y.; Fang, Y.; Yu, L.; Cheng, G.; Pan, Z.; Hu, G. Adsorption and oxidation of arsenic by two kinds of $\beta-\mathrm{MnO}_{2}$. J. Hazard. Mater. 2019, 373, 232-242. [CrossRef] [PubMed]

63. Barbosa, P.F.P.; Cumba, L.R.; Andrade, R.D.A.; do Carmo, D.R. Chemical modifications of cyclodextrin and chitosan for biological and environmental applications: Metals and organic pollutants adsorption and removal. J. Polym. Environ. 2019, 27, 1352-1366. [CrossRef] 